\title{
Effect of Wholemeal Durum Wheat Varieties on Bread Quality
}

\author{
Alessandra Danza1, Marcella Mastromatteo', Lucia Lecce1, Sara Spinelli1, Janine Laverse1, \\ Vincenzo Lampignano ${ }^{1}$, Francesco Contò ${ }^{2}$, Matteo Alessandro Del Nobile ${ }^{1}$ \\ ${ }^{1}$ Department of Agriculture, Food and Environment Science, University of Foggia, Foggia, Italy \\ ${ }^{2}$ Department of Economics, University of Foggia, Foggia, Italy \\ Email: matteo.delnobile@unifg.it
}

Received 9 March 2014; revised 9 April 2014; accepted 16 April 2014

Copyright (C) 2014 by authors and Scientific Research Publishing Inc.

This work is licensed under the Creative Commons Attribution International License (CC BY). http://creativecommons.org/licenses/by/4.0/

c) (i) Open Access

\begin{abstract}
In this work the effect of six varieties of durum wheat semolina on the bread physico-chemical and sensorial properties was addressed. In particular, whole grains of durum wheat (Anco Marzio, Claudio, Core, Iride, Saragolla and Cappelli) were finely milled by using an ancient stone milling system. Texture analysis was carried out on both dough and bread samples to evaluate their firmness. Furthermore, tomographic analysis was performed on the bread samples in order to provide a more detailed view of their texture. The Glucose Equivalent, the chemical and the sensory analyses of the bread were also determined. Results highlighted that the lowest Glucose Equivalent value was achieved in bread produced with the Anco Marzio cultivar, which appeared instead the worst in terms of texture. Among the investigated samples, bread from the Cappelli variety showed good structural characteristic, a moderate Glucose Equivalent compared to the reference sample (CTRL) and the highest sensory quality.
\end{abstract}

\section{Keywords}

Bread, Nutritional Properties, Physicochemical Properties, Sensory Analysis, Texture

\section{Introduction}

The wheat belongs to the genus Triticum among those cultivable species, indicated by the collective term Triticum sativum, the most important are the Triticum aestivum (vulgare), which constitutes the so-called soft wheat, Triticum compactum and Triticum durum, which constitutes the most known durum wheat.

The structure of the wheat grain can be distinguished in three main parts. The outer layer consisting of a protective casing that contains a fair amount of vitamins and mineral substances, commonly called fiber due to his 
fibrous nature. The largest part of the grain is occupied by the endosperm, characterized by the presence of starch and protein from which the gluten dough is formed, but deficient in vitamins and minerals. Finally, the grain is constituted by the germ, which contains a large number of enzymes, two important proteins (gliadin and glutenin), vitamins, mineral salts and oil very rich in vitamin $\mathrm{E}$.

It is well known that the characteristics of flours depend not only on the properties of the raw material but also from the technological process of milling, which is often held responsible for the depletion of the nutritional properties of the flours. The modern roller milling process has replaced the stone mill and is based on the principle of separate as much as possible the endosperm from the other parts of the caryopsis. In fact, the most refined flour (white flour) is the poorest of minerals, vitamins and amino acids in contrast to stone milled flours. In the production of wholemeal bread the commercial practice commonly employs refined flour of wheat or other cereals with the addition of bran cereal as whole wheat flour may not have the suitable technological characteristics.

The resulting products from the cereals processing are increasingly at the centre of attention due to their high content of useful substances for which recent studies have proven beneficial effects on the human organism. For instance, folic acid is important for the functioning of nervous system at all ages [1] due to the free radical scavenging property [2] and can thus be considered as an effective antioxidant. Some wholegrain foods are also characterized by inducing a low glycemic response, but not all and this is related to differences in particle size, which is not included in the wholegrain definition. Dietary fiber may regulate body weight through intrinsic effects and hormonal responses. High-fiber foods may promote satiation (intrameal satiety) and satiety (intermeal satiety) due to its bulking and lower energy density.

According to Kihlberg et al. [3], milling is a technological process and the milling effects on flour characteristics are well known [4]-[6], although the effects on the sensory qualities of the bread have not been described. Objective methods to measure sensory properties such as taste, smell and consistency are important complements to nutritional and technical attributes when it comes to assessing the quality of foodstuffs.

To our knowledge, there are no breads on the market that are made of $100 \%$ wholemeal wheat flour and have low glycemic responses. To this aim, the goal of the study was to evaluate the structural, sensory and nutritional properties of wholemeal bread manufactured by using different varieties of durum wheat. In particular, the effect of old and modern cultivars of durum wheat on bread quality was investigated. The characteristics of the investigated bread samples were compared with that of bread based on commercial semolina mixtures.

\section{Materials and Methods}

\subsection{Raw Materials}

Durum wheat wholemeal semolina obtained from five Italian modern cultivars (Anco Marzio, Claudio, Core, Iride, Saragolla) and one from old cultivar (Cappelli) were used in this study for the bread manufacture. The durum wheat grains were provided by a local mill (Santacroce Giovanni s.p.a, Deliceto-Foggia, Italy) and milled by using a local stone mill (Bovino, Foggia, Italy). In the milling process was included a first stage of maceration in water of the grains, which were subsequently minced using a mill equipped with stone grinders.

A reference sample was also prepared using commercial durum wheat re-milled semolina that was bought from Tandoi Mill (Corato, Bari, Italy) (named as CTRL). Fresh compressed yeast, salt and extra virgin olive oil were bought from a local market, dried sourdough was supplied from Bongiovanni mill (Villanova Mondovi', Cuneo, Italy).

\subsection{Nutritional Properties}

The nutritional composition of the wholemeal semolina and bread was performed by evaluating the content of protein, fat, ash, total dietary fiber (TDF), soluble and insoluble dietary fiber (SDF and IDF). In addition, the available carbohydrate content $(\mathrm{ACH})$ and the moisture content were determined. The methodology used was according to Mastromatteo et al. [7]. All chemical analyses were made in triplicate.

\subsection{Breadmaking Process}

The bread was produced by a direct method and the stage of kneading, leavening and baking were performed by using a bakery pilot plant. The doughs were prepared by using the following ingredients: $2500 \mathrm{~g}$ of durum wheat 
wholemeal of each variety concerned, $75 \mathrm{~g}$ of fresh yeast, $75 \mathrm{~g}$ of salt, $75 \mathrm{~g}$ of dried yeast and $100 \mathrm{ml}$ of extra virgin olive oil. The optimum amount of water to be used for each sample was determined by preliminary tests.

Dough samples were obtained by mixing the salt and the optimum amount of water in a spiral mixer (Conti kneaders, Verona, Italy); subsequently all the other ingredients were added as described below. Initially, in order to adequately mix the ingredients with each other a low speed of kneading was used for 5 minutes. Once a homogeneous dough was obtained the speed was increased and the total processing time was 30 minutes for doughs obtained from the millstone semolina and 20 minutes for those obtained by conventional milling. Subsequently, the dough was cut into portions by $1500 \mathrm{~g}$, manually worked to form a loaf and placed to rise in a leavening chamber (Thermogel, Varese, Italy) at constant temperature of $30^{\circ} \mathrm{C}$ and relative humidity of $85 \%$. As can be seen in Table 1, each dough requested a specific period of leavening. The baking was carried out in an electric oven at $250^{\circ} \mathrm{C}$ for 55 minutes (ovens Europe, Vicenza, Italy).

Bread samples were made to cool at room temperature for about 2 hours and then were subjected to the instrumental, chemical and sensory analysis. All bread samples are listed in Table 1.

\subsection{Textural Properties}

\subsubsection{Dough Texture Analysis}

The dough tensile testing device was used to measure tensile properties of the investigated doughs. To this aim a Zwick/Roell model Z010 Texture Analyzer was used (Zwick Roell Italia S.r.l., Genova, Italia). The specimen preparation and the trial specifications were carried out as reported by Mastromatteo et al. [8].

\subsubsection{Crumb Texture Analysis}

Crumb firmness was evaluated by means of a Texture Analyzer (Zwick Roell Italia S.r.l., Genova, Italia). The bread samples were uniformly sliced into wedges of $15 \mathrm{~mm}$ thickness and cylindrical crumb samples $(28 \mathrm{~mm}$ diameter) were cut from the middle of each bread slice by using a circular cutter. The methodology used and the experimental conditions were according to Lampignano et al. [9].

\subsection{Tomographic Analysis}

For X-ray microtomographical analysis $(\mu \mathrm{CT})$ the bread samples were imaged under the same conditions, using the Skyscan 1172 high-resolution desktop X-ray microtomography system (Skyscan, Belgium). The bread samples were prepared as those used in the compression analysis and were placed on a round plate; the source and the detector were fixed, while the sample was rotated during measurement. Power settings of $100 \mathrm{kVp}$ and 100 $\mu \mathrm{A}$ were used. A CCD camera with $2000 \times 1048$ pixels was used to record the transmission of the conical X-ray beam through all samples. The distance source-object-camera was adjusted to produce images with a pixel size of $2 \mu \mathrm{m}$. Four-frame averaging, a rotation step of $0.40^{\circ}$ and an exposure time of $1767 \mathrm{~ms}$ were chosen to minimize the noise, covering a view of $180^{\circ}$. Scan time, on average, required 30 minutes. A set of flat cross section images was obtained for each sample after tomographical reconstruction by the reconstruction software NRecon (Skyscan). For image processing and analysis the skyscan software, CT-Analyser (CTAn) was used. For data

Table 1. Formulations of the investigated bread samples.

\begin{tabular}{|c|c|c|c|c|c|}
\hline Sample & $\begin{array}{l}\text { Wholemeal } \\
\text { Semolina (g) }\end{array}$ & $\begin{array}{c}\text { Water Content } \\
\text { (mL) }\end{array}$ & $\begin{array}{c}\text { Yeast, Salt, } \\
\text { Sourdough (g) }\end{array}$ & $\begin{array}{l}\text { Leavening } \\
\text { Time (min) }\end{array}$ & $\begin{array}{c}\text { Cooking } \\
\text { Temperature }\left({ }^{\circ} \mathrm{C}\right)\end{array}$ \\
\hline Cappelli & 2500 & 1650 & 75 & 45 & 250 \\
\hline Core & 2500 & 1650 & 75 & 60 & 250 \\
\hline Iride & 2500 & 1650 & 75 & 60 & 250 \\
\hline Saragolla & 2500 & 1900 & 75 & 50 & 250 \\
\hline Anco Marzio & 2500 & 1600 & 75 & 30 & 250 \\
\hline Claudio & 2500 & 1500 & 75 & 50 & 250 \\
\hline CTRL & 2500 & 1650 & 75 & 50 & 250 \\
\hline
\end{tabular}


analysis, prior to 3D reconstruction, a component-labelling algorithm, available within CTAn, was used to isolate the largest 3D connected structures. The following five tomographical geometric parameters were measured using the CTAn software (Skyscan): Percent object volume (POV), Object surface/volume ratio (OSVR), Fragmentation index (FI), Structure Thickness (St.Th) and Structure Separation (St.Sp). Where, 1) Percentage object volume is the proportion of the VOI (volume of interest) i.e. pores; 2) Object surface/volume ratio is the basic parameter in characterising the complexity of the structures and is also the basis of model-dependent estimates of thickness i.e. size and distribution of the pores present in each sample; 3) Fragmentation index is an index of connectivity of the structures, which was developed and defined by Hahn et al. [10], 4) Structure thickness calculates or estimates the average structure diameter of the object from 2D measurements and 5) Structure separation is essentially the average thickness (average distance) of the structure separating the pores.

\subsection{Glucose Equivalent of Bread}

\section{In Vitro Digestion}

The digestion was carried out as described by Chillo et al. [11] and Monro et al. [12] with slight modifications. The methodology used and the experimental conditions were according to Mastromatteo et al. [7]. The results were plotted as Glucose Equivalent (GE) (mg) per g of sample vs time.

\subsection{Sensory Analysis}

Ten panelists were used for the assessment of the sensory attributes of the bread samples. They were trained in the sensory analysis, lexicon and methodology (ISO 1998). The bread samples were evaluated for attributes such as color, appearance, crust and crumb firmness, large bubbles and overall acceptability by using a nine-point scale ranging from like extremely (9) to dislike extremely (1) [8] [13]-[15]. The experiment was designed so that two replicates were obtained for each type of bread.

\subsection{Statistical Analysis}

The statistical analysis, made to determine the significant differences between the bread samples under investigation, was performed through a one-way variance analysis (ANOVA). Significant differences between means were identified by Duncan's multiple range tests (considered significant for $\mathrm{p}<0.05$ ). All statistical analyses were carried out by using STATISTICA 7.1 (Statsoft, Inc., Tulsa, OK, USA).

\section{Results and Discussion}

\subsection{Nutritional Properties}

In Table 2(a), Table 2(b) the nutritional composition of both the semolina samples and the manufactured bread were presented. Regarding the semolina (Table 2(a)), all samples had a high ash content, with values ranging from $1.54 \%$ to $1.43 \%$ (Iride and Anco Marzio varieties, respectively). The lowest value was recorded for the Claudio variety (1.19\%). The protein content was the highest for the Anco Marzio sample (13.71\%), but it was near to that of the other varieties analyzed. The lowest values were found for the Core and Iride cultivars and the CTRL sample (12.13\%, $12.30 \%$ and $12.25 \%$, respectively). Concerning the ACH content, all samples showed lower values of this parameter with respect to the CTRL sample (76.27\%). Specifically, the Anco Marzio, Claudio and Saragolla varieties recorded the lowest values (as low as 62.33\%). In this regard, it is necessary to consider that, unlike what happens in a traditional roller milling, in a stone milling process the semolina has not been fully milled [16], so the glucose and fructose present in the seed are not completely available. Table 2(a) also showed significant differences about the IDF content obtained from all the semolina samples. In particular, the wholemeal samples recorded values significantly higher (up to 9.42\%) than the CTRL sample (2.88\%). The same results were found for both the TDF and SDF content because of the fibers present in the seeds peripheral layers of the wholemeal semolina.

Table 2(b) also listed the nutritional properties of the bread manufactured with the six wheat cultivars investigated. As was found for the semolina, the bread based on Anco Marzio cultivar had the highest value of the protein content (13.59\%), followed by the Claudio cultivar based bread (13.13\%). The other breads showed values ranging between $11.47 \%$ and $12.81 \%$ and near to the reference sample CTRL (12.64\%). The ash content 
Table 2. (a) Nutritional analysis of the semolina samples*; (b) Nutritional analysis of the bread samples*.

(a)

\begin{tabular}{|c|c|c|c|c|c|c|c|c|}
\hline Samples & Moisture (\%) & Lipids (\%) & Proteins (\%) & Ash (\%) & $\mathrm{ACH}(\%)$ & TDF (\%) & IDF (\%) & SDF (\%) \\
\hline Anco Marzio & $19.12^{\mathrm{a}} \pm 0.30$ & $0.992^{\mathrm{a}} \pm 0.053$ & $13.71^{\mathrm{a}} \pm 0.16$ & $1.43^{\mathrm{a}}=$ & & & & \\
\hline Cappelli & $14.73^{\mathrm{b}} \pm 0.23$ & $977^{\mathrm{a}} \pm 0.09$ & $13.02^{\mathrm{a}, \mathrm{b}} \pm 0.01$ & $1.46^{\mathrm{a}, \mathrm{b}} \pm 0.01$ & $69.95^{\mathrm{b}} \pm 0.60$ & & & 2.32 \\
\hline Claudio & & $0.837^{\mathrm{c}} \pm 0.056$ & $13.17^{\mathrm{a}, \mathrm{b}} \pm 0.04$ & & & & $6.91^{\mathrm{C}} \pm 0.01$ & \\
\hline Core & & & & $1.50^{\mathrm{b}, \mathrm{c}} \pm 0.03$ & $72.65^{\mathrm{b}} \pm 0.41$ & & $9.11^{\mathrm{d}} \pm 0.03$ & $2.57^{\mathrm{f}} \pm 0.01$ \\
\hline Iride & & $1.239^{\mathrm{d}} \pm 0$ & $12.30^{\mathrm{a}, \mathrm{b}} \pm 0$ & & & $11.22^{\mathrm{c}} \pm 0.05$ & & \\
\hline Saragolla & $15.19^{\mathrm{b}, \mathrm{c}} \pm 0.18$ & $1.085^{\mathrm{a}} \pm 0.009$ & $13.15^{\mathrm{a}, \mathrm{b}} \pm 0.73$ & $1.51^{\mathrm{c}} \pm 0.01$ & $64.14^{\mathrm{a}} \pm 1.42$ & $10.78^{\mathrm{b}} \pm 0.05$ & $8.72^{\mathrm{f}} \pm 0.03$ & $2.06^{\mathrm{b}} \pm 0.02$ \\
\hline TRI & $13.82^{\mathrm{e}} \pm 0.14$ & $1.450^{\mathrm{b}} \pm 0.009$ & $12.25^{\mathrm{b}} \pm 0.13$ & $1.51^{\mathrm{C}} \pm 0.00$ & $76.27^{\mathrm{c}} \pm 0.71$ & $4.44^{\mathrm{e}} \pm 0.02$ & $2.88^{g} \pm 0.00$ & $1.56^{\mathrm{c}} \pm 0.02$ \\
\hline
\end{tabular}

${ }^{*}$ Mean of triplicate determinations on a dry-weight basis. ${ }^{a-d}$ Mean in the same column followed by different superscript letters differs significantly (p $<0.05)$.

(b)

\begin{tabular}{cccccccc}
\hline Samples & Lipids (\%) & Proteins (\%) & Ash (\%) & ACH (\%) & TDF (\%) & IDF (\%) & SDF (\%) \\
\hline Anco Marzio & $1.115^{\mathrm{a}} \pm 0.074$ & $13.59^{\mathrm{a}} \pm 0.02$ & $4.36^{\mathrm{a}} \pm 0.01$ & $67.65^{\mathrm{a}, \mathrm{b}} \pm 3.07$ & $12.15^{\mathrm{a}} \pm 0.19$ & $10.26^{\mathrm{a}} \pm 0.02$ & $1.89^{\mathrm{a}, \mathrm{b}} \pm 0.20$ \\
Cappelli & $1.223^{\mathrm{a}, \mathrm{b}} \pm 0.099$ & $12.29^{\mathrm{c}} \pm 0.00$ & $4.33^{\mathrm{d}} \pm 0.01$ & $65.86^{\mathrm{a}, \mathrm{b}} \pm 0.59$ & $12.01^{\mathrm{a}} \pm 0.03$ & $9.32^{\mathrm{f}} \pm 0.00$ & $2.69^{\mathrm{d}} \pm 0.03$ \\
Claudio & $1.288^{\mathrm{b}} \pm 0.055$ & $13.13^{\mathrm{a}, \mathrm{d}} \pm 0.30$ & $4.25^{\mathrm{c}} \pm 0.00$ & $69.41^{\mathrm{b}, \mathrm{c}} \pm 0.64$ & $11.36^{\mathrm{d}} \pm 0.08$ & $9.51^{\mathrm{g}} \pm 0.08$ & $1.85^{\mathrm{a}, \mathrm{b}} \pm 0.00$ \\
Core & $1.224^{\mathrm{a}, \mathrm{b}} \pm 0.053$ & $11.47^{\mathrm{b}} \pm 0.11$ & $4.60^{\mathrm{f}} \pm 0.02$ & $68.36^{\mathrm{a}, \mathrm{b}} \pm 0.83$ & $12.56^{\mathrm{b}} \pm 0.45$ & $10.90^{\mathrm{c}} \pm 0.09$ & $1.65^{\mathrm{a}, \mathrm{b}} \pm 0.54$ \\
Iride & $1.133^{\mathrm{a}} \pm 0.119$ & $12.81^{\mathrm{c}, \mathrm{d}} \pm 0.04$ & $4.43^{\mathrm{e}} \pm 0.01$ & $68.05^{\mathrm{a}, \mathrm{b}} \pm 2.46$ & $12.49^{\mathrm{b}} \pm 0.05$ & $10.50^{\mathrm{b}} \pm 0.08$ & $1.99^{\mathrm{b}, \mathrm{c}} \pm 0.03$ \\
Saragolla & $1.116^{\mathrm{a}} \pm 0.011$ & $12.74^{\mathrm{c}, \mathrm{d}} \pm 0.66$ & $4.36^{\mathrm{a}} \pm 0.01$ & $65.02^{\mathrm{a}} \pm 2.22$ & $14.24^{\mathrm{e}} \pm 0.06$ & $11.94^{\mathrm{d}} \pm 0.05$ & $2.30^{\mathrm{c}} \pm 0.01$ \\
CTRL & $1.450^{\mathrm{c}} \pm 0.019$ & $12.64^{\mathrm{c}, \mathrm{d}} \pm 0.09$ & $2.79^{\mathrm{b}} \pm 0.01$ & $72.28^{\mathrm{c}} \pm 1.76$ & $5.36^{\mathrm{c}} \pm 0.07$ & $3.85^{\mathrm{e}} \pm 0.05$ & $1.52^{\mathrm{a}} \pm 0.02$ \\
\hline
\end{tabular}

"Mean of triplicate determinations on a dry-weight basis. ${ }^{\mathrm{a}-\mathrm{d}}$ Mean in the same column followed by different superscript letters differs significantly (p $<0.05)$.

for all wholemeal bread samples investigated was higher (about 4\%) than the CTRL sample (2.79\%). The Saragolla sample showed the highest TDF content (14.24\%), whereas an amount of TDF of about $12 \%$ was found for all the other wholemeal bread samples.

However, the fiber content of the abovementioned samples was the highest in comparison to the CTRL sample (5.36\%). As a consequence, the highest content of both SDF and IDF were found for all wholemeal bread with respect to the CTRL sample. Specifically, the SDF amount was about $2 \%$ in all wholemeal bread samples against the $1.52 \%$ of the CTRL sample. Exclusively in the Cappelli and Saragolla samples the highest value was observed (2.69\% and $2.30 \%$, respectively). Regarding the bread ACH content, significant differences were observed between the samples produced with the six wheat varieties and the CTRL sample. The abovementioned differences could be due to the fact that the rise in the dietary fibre concentration determined the drop in the carbohydrate content, which are responsible for the increase in the glycemic response. It is worth noting that the Cappelli (65.86\%) and Saragolla (65.02\%) samples had the lowest content of the abovementioned parameter.

In order to evaluate the effect of the different cultivar on the in vitro glycemic response of the manufactured bread, the Glucose Equivalent was also evaluated (Table 3). The use of the stone milling process made possible to produce semolina with a high content of fibers and reduced GE. In fact, with the exception of the Iride sample that recorded a high value of the GE parameter (equal to 97) and statistically similar to the CTRL sample, there were no significant differences among most of the tested samples, and generally they showed GE values of about 86. The bread with the lowest value of GE was manufactured with the Anco Marzio variety (67). 
Table 3. Glucose equivalent of the bread samples.

\begin{tabular}{cc}
\hline Samples & GE \\
\hline Anco Marzio & $67^{\mathrm{a}} \pm 0.93$ \\
Cappelli & $85^{\mathrm{b}} \pm 1.40$ \\
Claudio & $85^{\mathrm{b}} \pm 0.53$ \\
Core & $87^{\mathrm{b}} \pm 1.58$ \\
Iride & $97^{\mathrm{c}} \pm 2.95$ \\
Saragolla & $87^{\mathrm{b}} \pm 0.83$ \\
CTRL & $100^{\mathrm{c}} \pm 0.00$ \\
\hline
\end{tabular}

${ }^{a-d}$ Mean in the same column followed by different superscript letters differs significantly $(\mathrm{p}<0.05)$.

\subsection{Sensorial and Physical Properties of Bread}

\subsubsection{Sensory Analysis}

The organoleptic characteristics of wholemeal bread made with durum wheat semolina from six different varieties (Anco Marzio, Claudio, Core, Iride, Saragolla and Cappelli) were evaluated through a sensory analysis.

As can be seen in Table 4, among all manufactured wholemeal bread samples the maximum score of overall acceptability was obtained for the Cappelli sample (6.70). This sample showed a good color, appearance and a very crisp crust, but its most positive result was mainly attributable to the presence of a soft crumb characterized by a homogenous large bubbles. Figure 1 shows the picture of the Cappelli bread sample. The finding obtained was in accordance with what was observed from the structural analyses of the bread described below. In fact, only the Cappelli sample showed the best results in terms of texture quality, being the dough and crumb quite elastic and soft, respectively. In addition, the Core and Anco Marzio samples showed a score slightly above the limit of product acceptability (5.60 and 5.0, respectively). In this case, even though they recorded a good general appearance, the sensory parameters that had a negative impact on the final score were the consistency of the crumb and the presence of very few bubbles. Regarding the other samples (Claudio, Iride and Saragolla), a score significantly below the limit of product acceptability threshold was recorded. In particular, the Iride sample was the worst due to the presence of a very compact crumb without a well-defined alveolation. These last parameters have affected also the consistency of the crust and the appearance of the bread, both judged just passable.

According to various research works reported in literature, when insoluble fibres such as wheat, hulls, pea, sugarcane bagasse or carob were added upon bread a decrease on the specific volume of the final product was observed [17]-[21]. A possible reason is that the fibre interacts with the gluten and led to a decrease in the dough gas retention capacity [14]. Most probably, this phenomenon contributed to the formation of breadcrumb that appeared low in volume and with few and small bubbles.

\subsubsection{Instrumental Analysis}

\section{1) Dough Texture Analysis}

Table 5 shows the results of the textural analysis carried out on doughs produced with different variety of durum wheat semolina from stone milling process. In particular, dough tensile test represents an indirect measure that allows assessing the ability of the dough to the kneading process. In fact, those characterized by a high elongation at break and require low forces to be deformed are doughs from which can be obtained good finished products [22]. In our work, the properties of the doughs were evaluated by means two parameters, the strength at break $\left(F_{\text {break }}\right)$ and the deformation at break $\left(\operatorname{Strain}_{\text {break }}\right)$. The first evaluates the force that must be applied in order to break the sample while the second assess the deformation at which the rupture occurs in the sample. Moreover, the tenacity, measured as the area under the stress-strain curve and calculated by an integration procedure, was also evaluated. The samples analyzed were divided into two groups. In the first group, it is possible to observe the Cappelli, Claudio and Core samples which required the greatest force to be deformed until failure ( $F_{\text {break }}$ equal to $0.084 \mathrm{~N}, 0.075 \mathrm{~N}$ and $0.068 \mathrm{~N}$, respectively). This behavior was due to their greater toughness and resistance, quite close to the CTRL sample $(0.166 \mathrm{~N})$. In fact, it is possible to note from Table 5 that Cappelli, 
Table 4. Sensory characteristics of the investigated bread samples.

\begin{tabular}{ccccccc}
\hline Samples & Color & Appearance & Crust Firmness & Crumb Firmness & Large bubbles & Overall Quality \\
\hline Cappelli & $7.10^{\mathrm{a}, \mathrm{b}} \pm 0.22$ & $6.60^{\mathrm{a}} \pm 0.42$ & $7.20^{\mathrm{a}} \pm 0.27$ & $6.50^{\mathrm{a}} \pm 0.35$ & $6.60^{\mathrm{a}} \pm 0.42$ & $6.70^{\mathrm{a}} \pm 0.27$ \\
Core & $7.60^{\mathrm{a}} \pm 0.42$ & $7.20^{\mathrm{a}, \mathrm{c}} \pm 0.27$ & $7.10^{\mathrm{a}, \mathrm{b}} \pm 0.42$ & $5.20^{\mathrm{b}} \pm 0.27$ & $5.10^{\mathrm{c}} \pm 0.22$ & $5.60^{\mathrm{b}} \pm 0.42$ \\
Iride & $7.40^{\mathrm{a}} \pm 0.22$ & $5.80^{\mathrm{b}} \pm 0.76$ & $5.00^{\mathrm{c}} \pm 0.00$ & $3.10^{\mathrm{c}} \pm 0.22$ & $3.00^{\mathrm{d}} \pm 0.00$ & $3.20^{\mathrm{c}} \pm 0.27$ \\
Saragolla & $7.50^{\mathrm{a}} \pm 0.50$ & $5.10^{\mathrm{b}} \pm 0.22$ & $6.80^{\mathrm{a}, \mathrm{b}, \mathrm{d}} \pm 0.27$ & $4.10^{\mathrm{d}} \pm 0.22$ & $4.20^{\mathrm{e}} \pm 0.27$ & $4.30^{\mathrm{d}} \pm 0.27$ \\
Anco Marzio & $6.50^{\mathrm{b}} \pm 0.35$ & $5.40^{\mathrm{b}} \pm 0.42$ & $6.40^{\mathrm{d}} \pm 0.22$ & $5.70^{\mathrm{b}} \pm 0.57$ & $5.60^{\mathrm{b}} \pm 0.22$ & $5.00^{\mathrm{e}} \pm 0.0$ \\
Claudio & $7.40^{\mathrm{a}} \pm 0.42$ & $6.70^{\mathrm{a}} \pm 0.27$ & $6.60^{\mathrm{b}, \mathrm{d}} \pm 0.42$ & $4.00^{\mathrm{d}} \pm 0.0$ & $4.10^{\mathrm{e}} \pm 0.22$ & $4.10^{\mathrm{d}} \pm 0.42$ \\
CTRL & $7.20^{\mathrm{a}, \mathrm{b}} \pm 0.45$ & $7.50^{\mathrm{c}} \pm 0.22$ & $7.00^{\mathrm{a}, \mathrm{b}} \pm 0.35$ & $7.90^{\mathrm{e}} \pm 0.22$ & $7.80^{\mathrm{f}} \pm 0.45$ & $7.70^{\mathrm{f}} \pm 0.45$ \\
\hline
\end{tabular}

${ }^{\mathrm{a}-\mathrm{d}}$ Mean in the same column followed by different superscript letters differs significantly $(\mathrm{p}<0.05)$.

Table 5. Parameters of the tension test for the dough samples.

\begin{tabular}{|c|c|c|c|c|}
\hline Samples & $F_{\max }(\mathrm{N})$ & $F_{\text {break }}(\mathrm{N})$ & Strain $_{\text {break }}(\%)$ & Tenacity (N'mm) \\
\hline Cappelli & $0.169^{\mathrm{a}} \pm 0.015$ & $0.084^{\mathrm{a}} \pm 0.007$ & $25.44^{\mathrm{a}} \pm 1.76$ & $2.59^{\mathrm{a}} \pm 0.16$ \\
\hline Core & $0.148^{\mathrm{a}} \pm 0.018$ & $0.068^{\mathrm{a}} \pm 0.010$ & $23.64^{\mathrm{a}, \mathrm{c}} \pm 2.46$ & $1.94^{\mathrm{a}, \mathrm{b}} \pm 0.62$ \\
\hline Iride & $0.088^{\mathrm{b}, \mathrm{c}} \pm 0.007$ & $0.044^{\mathrm{b}, \mathrm{c}} \pm 0.003$ & $16.99^{\mathrm{b}} \pm 1.61$ & $1.12^{\mathrm{b}, \mathrm{c}} \pm 0.36$ \\
\hline Saragolla & $0.059^{\mathrm{b}} \pm 0.007$ & $0.028^{\mathrm{b}} \pm 0.004$ & $19.38^{\mathrm{b}, \mathrm{c}} \pm 1.95$ & $0.78^{\mathrm{C}} \pm 0.11$ \\
\hline Anco Marzio & $0.101^{\mathrm{c}} \pm 0.011$ & $0.050^{c} \pm 0.005$ & $19.62^{\mathrm{b}, \mathrm{c}} \pm 1.82$ & $1.13^{\mathrm{b}, \mathrm{c}} \pm 0.11$ \\
\hline Claudio & $0.149^{\mathrm{a}} \pm 0.017$ & $0.075^{\mathrm{a}} \pm 0.008$ & $21.64^{\mathrm{a}, \mathrm{b}, \mathrm{c}} \pm 1.86$ & $2.18^{\mathrm{a}, \mathrm{b}} \pm 0.33$ \\
\hline CTRL & $0.339^{\mathrm{d}} \pm 0.040$ & $0.166^{\mathrm{d}} \pm 0.020$ & $45.26^{\mathrm{d}} \pm 5.15$ & $9.59^{\mathrm{d}} \pm 1.57$ \\
\hline
\end{tabular}

${ }^{a-d}$ Mean in the same column followed by different superscript letters differs significantly $(\mathrm{p}<0.05)$.

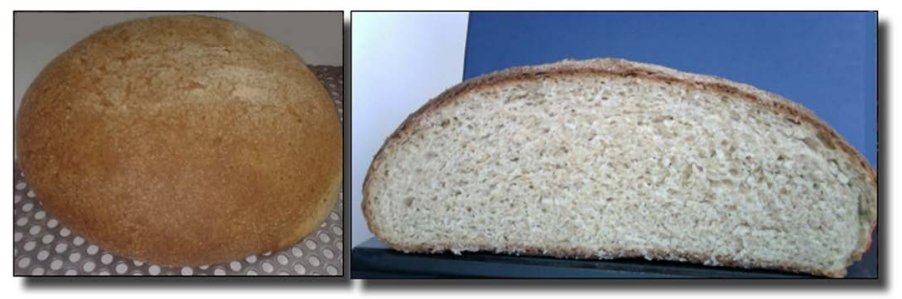

Figure 1. Wholemeal bread: cv. Cappelli.

Claudio and Core samples had a higher tenacity values with respect to the Iride, Anco Marzio and Saragolla samples. In addition, the abovementioned parameter for the CTRL sample was much higher if compared to the other samples $(9.59 \mathrm{Nmm})$. Regarding the deformation at break $\left(\right.$ Strain $\left._{\text {break }}\right)$ for the Cappelli, Claudio and Core samples, it ranged between $25 \%$ and $21 \%$. The highest value was recorded for the CTRL sample (45\%). In the second group, there were the Anco Marzio, Iride and Saragolla samples that required $F_{\text {break }}$ of $0.050 \mathrm{~N}, 0.044 \mathrm{~N}$ and $0.028 \mathrm{~N}$, respectively. In this case, the doughs were less tenacious and were broken immediately as soon as the force necessary to deform them was applied.

This behaviour was also confirmed by the tenacity parameter that reached values of just $0.78-1.1 \mathrm{Nmm}$. In general, Strain ${ }_{\text {break }}$ values of about $17 \%$ and $19 \%$ were observed for these samples. The greater rigidity of the doughs obtained from stone milled semolina was probably due to the high content in different size fibers. As reported in literature, a negative effect on the characteristics of doughs and bread by replacing the flour with dietary fiber was observed. Specifically, the addition of sufficient quantities of fiber to provide physiological ben- 
efits would result in alterations of the interactions that take place between gluten and starch granules dispersed in the dough, interaction closely related to the rheological properties of the dough [23]. Moreover, the gluten proteins are characterized by strong aggregation tendencies resulting from their hydrogen bonding potential [24]. Their solubility and inter-protein bonding are probably the main factors responsible for the unique visco-elastic properties of wheat gluten. Disulfide bonds, hydrogen bonds and hydrophobic interactions are considered the most important associative forces in gluten structure.

Hence, the differences in the rheological behavior were related to the number of rheologically effective disulfide cross-links, and that the viscous flow was the result of breaking and reforming of these disulfide bonds via a thiol-disulfide interchange reaction. It is worth noting that the gluten properties depend strongly on the durum wheat variety that may establish a different equilibrium between gluten, starch and fiber in the water competition [25].

\section{2) Crumb Texture Analysis}

The force required to compress a sample of breadcrumb at $50 \%$ of its initial shape was taken as reference to express the hardness of the bread. Table 6 shows the results of the compression tests performed on breadcrumb manufactured with different variety of durum wheat. Results highlighted that bread made with Cappelli and Core semolina recorded a softer crumb with respect to the other wholemeal samples. These crumb samples required low forces to be compressed by $50 \%$ compared to their initial shape (13.18N and $16.95 \mathrm{~N}$, respectively). Appears unusual to note how the Core sample recorded in the compression analysis a fairly good softness of the crumb, but unfortunately this feature was not evaluated positively by the panelists involved in the sensory analysis. In accordance to what was observed with the sensory analysis, the remaining bread varieties showed a crumb less soft and very compact, in fact they required compression forces ranged between 20.90N (Claudio sample) and $28.27 \mathrm{~N}$ (Saragolla sample). In contrast, the CTRL sample showed a very soft and well-structured crumb and was compressed with the lowest force (just 6N) compared to all analyzed samples.

\section{3) Tomographic analysis}

Table 7 shows the average values obtained for the five tomographical parameters, POV, OSVR, FI, St.Th and St.Sp, and the results of the statistical analysis. Figure 2 shows examples of the set of flat cross sections obtained for each sample. As stated above, the POV parameter was calculated for each image as a representation of the percentage total pore content within the sample. As can be noted from Table 7, all the samples have statistically equal POV values, except for the sample Iride that has the lowest and highly significantly different POV value. The POV results suggest that the bread produced from Iride variety is less porous in structure with respect to the other samples. The parameter OSVR indicates the ratio of the surface of the cell walls to the total volume of the object and is inversely proportional to St.Th, the average diameter of the pores present in the sample. A high OSVR value (with respect to other samples in the same group) indicates a high distribution of pores with smaller diameter. As can be noted from the table, the Iride, Cappelli and Claudio samples have the highest OSVR values (although statistically equal to that of the CTRL) and therefore the lowest St.Th value meaning that these samples have a high distribution of very small pores, whereas the remaining samples have low OSVR values and the highest St.Th values that are statistically equal, indicating in this case that these samples have a

Table 6. Parameters of the compression test for the bread samples.

\begin{tabular}{cc}
\hline & ${ }^{*} F_{50 \%}(\mathrm{~N})$ \\
\hline Cappelli & $13.18^{\mathrm{a}} \pm 1.93$ \\
Core & $16.95^{\mathrm{b}} \pm 1.85$ \\
Iride & $24.40^{\mathrm{d}} \pm 2.73$ \\
Saragolla & $28.27^{\mathrm{c}} \pm 2.99$ \\
Anco Marzio & $23.46^{\mathrm{d}} \pm 1.64$ \\
Claudio & $20.90^{\mathrm{d}} \pm 1.64$ \\
CTRL & $6.17^{\mathrm{e}} \pm 1.39$ \\
\hline
\end{tabular}

${ }^{\mathrm{a}-\mathrm{e}}$ Mean in the same column followed by different superscript letters differs significantly ( $<0.05$ ); ${ }^{*}$ The samples have been compressed to $50 \%$ strain. 
Table 7. Microstructural parameters of the bread samples.

\begin{tabular}{cccccc}
\hline Samples & POV $(\%)$ & OSVR $(1 / \mathrm{mm})$ & FI $(1 / \mathrm{mm})$ & St.Th $(\mathrm{mm})$ & St.Sp $(\mathrm{mm})$ \\
\hline Cappelli & $50.22^{\mathrm{a}} \pm 1.73$ & $11.97^{\mathrm{b}} \pm 1.10$ & $-5.84^{\mathrm{b}} \pm 1.76$ & $0.54^{\mathrm{b}} \pm 0.04$ & $0.35^{\mathrm{e}} \pm 0.01$ \\
Core & $47.98^{\mathrm{a}} \pm 2.04$ & $7.21^{\mathrm{a}} \pm 0.47$ & $0.90^{\mathrm{a}} \pm 0.54$ & $0.79^{\mathrm{a}} \pm 0.06$ & $0.49^{\mathrm{b}, \mathrm{c}} \pm 0.03$ \\
Iride & $29.26^{\mathrm{b}} \pm 3.03$ & $10.18^{\mathrm{b}, \mathrm{c}} \pm 0.64$ & $4.15^{\mathrm{d}} \pm 0.72$ & $0.58^{\mathrm{b}} \pm 0.04$ & $0.61^{\mathrm{d}} \pm 0.03$ \\
Saragolla & $43.52^{\mathrm{a}} \pm 2.77$ & $7.66^{\mathrm{a}} \pm 0.34$ & $1.61^{\mathrm{a}} \pm 0.83$ & $0.77^{\mathrm{a}} \pm 0.06$ & $0.52^{\mathrm{c}} \pm 0.02$ \\
Anco Marzio & $42.11^{\mathrm{a}} \pm 4.28$ & $7.46^{\mathrm{a}} \pm 1.35$ & $1.99^{\mathrm{a}} \pm 0.51$ & $0.75^{\mathrm{c}} \pm 0.13$ & $0.58^{\mathrm{d}} \pm 0.03$ \\
Claudio & $44.00^{\mathrm{a}} \pm 4.03$ & $10.38^{\mathrm{b}} \pm 1.07$ & $-1.13^{\mathrm{c}} \pm 0.35$ & $0.60^{\mathrm{b}, \mathrm{c}} \pm 0.08$ & $0.42^{\mathrm{a}} \pm 0.02$ \\
CTRL & $44.85^{\mathrm{a}} \pm 9.61$ & $8.50^{\mathrm{a}, \mathrm{c}} \pm 1.46$ & $1.83^{\mathrm{a}} \pm 0.89$ & $0.80^{\mathrm{a}} \pm 0.13$ & $0.43^{\mathrm{a}, \mathrm{b}} \pm 0.07$
\end{tabular}

${ }^{\mathrm{a}-\mathrm{d}}$ Mean in the same column followed by different superscript letters differs significantly $(\mathrm{p}<0.05)$.
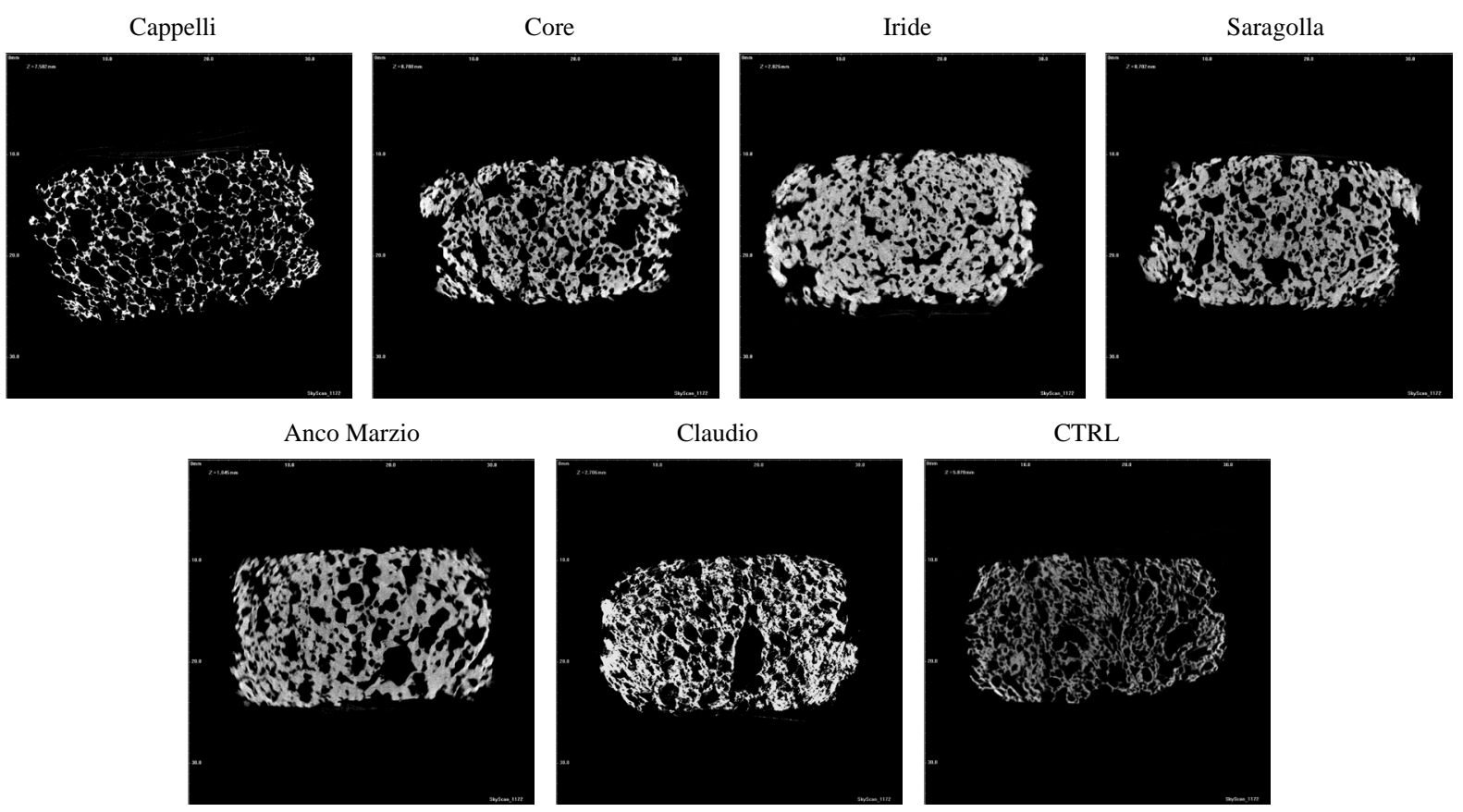

Figure 2. Flat cross sections of the bread samples.

very high distribution of larger pores with respect to all the samples in this group. For the St.Sp parameter, i.e. the average distance of the solid structure separating the pores, it can be noted that the samples Anco Marzio, Iride and Saragolla have the highest St.Sp value, this was as expected as these are the samples with the lowest POV values. With regards to the FI parameter, i.e. the index of connectivity and therefore a measure of relative convexity or concavity of the total pore surface, based on the principle that concavity indicates connectivity, and convexity indicates isolated disconnected structures [26]. A lower FI signifies pores that are connected to each other and has a negative index; on the other hand a higher FI indicates a more disconnected structure (i.e. pores that are distinctly separated from each other) and has a positive index. As it can be noted from the table the FI is positive for all samples except for the samples Cappelli and Claudio, suggesting that in general the bread produced using those varieties contains pores/holes that are distinctly separated from each other.

\subsection{Correlations}

In order to evaluate the relationships among the bread microstructural, mechanical and sensory parameters a statistical correlation was performed. The results obtained are shown in Table 8 and as can be observed from the 
Table 8. The correlation results for the structural and microstructural parameters of the investigated bread samples.

\begin{tabular}{|c|c|c|c|c|c|c|c|c|}
\hline & $F_{50 \%}$ & $\begin{array}{l}\text { Crumb } \\
\text { firmness }\end{array}$ & $\begin{array}{l}\text { Overall } \\
\text { quality }\end{array}$ & POV & OSVR & FI & St.Th & St.Sp \\
\hline$F_{50 \%}$ & 1 & $-0.8402^{*}$ & $-0.8850^{*}$ & -0.4466 & -0.2300 & 0.3417 & -0.0896 & $0.6326^{*}$ \\
\hline Crumb firmness & - & 1 & $0.9758^{*}$ & $0.6172^{*}$ & -0.0510 & -0.3418 & 0.3443 & $-0.5375^{*}$ \\
\hline Overall quality & - & - & 1 & $0.6890^{*}$ & 0.0072 & 0.4258 & 0.3095 & $-0.6456^{*}$ \\
\hline POV & - & - & - & 1 & -0.0358 & $-0.7260^{*}$ & 0.2224 & $-0.7801^{*}$ \\
\hline OSVR & - & - & - & - & 1 & $-0.6297^{*}$ & $-0.9314^{*}$ & $-0.5210^{*}$ \\
\hline FI & - & - & - & - & - & 1 & $0.5018^{*}$ & $0.8691^{*}$ \\
\hline St.Th & - & - & - & - & - & - & 1 & 0.2566 \\
\hline St.Sp & - & - & - & - & - & - & - & 1 \\
\hline
\end{tabular}

"highly and significantly correlated.

table significant correlations among the investigated parameters were observed.

An inverse correlation can be noted between $F_{50 \%}$ and crumb firmness that means a lower force is needed to deform a softer crumb. As a consequence, the overall quality of the bread increased and a very porous structure of the crumb was observed (i.e. high POV).

Regarding the microstructural parameters, an inverse correlation can be seen between St.Th, St.Sp and OSVR. This result suggests that the coalescence of the pores during the baking caused an increase of pore diameter and non-uniformity of the pores, therefore lower OSVR. It can also be noted that there is a significant correlation between the parameters St.Th and FI and St.Sp and FI suggesting that the connectivity of the pores present in the samples is strongly correlated to the pore separation and size. The only mechanical-microstructural correlation that exists can be found between St.Sp and F50\%, this is as expected because the more compact the structure the higher the force required to compress the sample.

\section{Conclusions}

Semolina from six different varieties of durum wheat (Anco Marzio, Cappelli, Claudio, Core, Iride and Saragolla) was used in this work for bread manufacturing, each obtained by subjecting the grain to the stone milling process.

The bread was analyzed in order to evaluate how the wheat variety and the milling system influenced the physical, nutritional and sensory characteristics of the final product. The results showed that the stone milled semolina allow obtaining bread with a low GE. Furthermore, among all the varieties investigated, the bread made with Anco Marzio semolina showed the lowest GE value (67) and was sensorially acceptable (5.00), but would require further optimization to maximize its organoleptic characteristics. Instead, the results of the structural analysis performed on dough and crumb indicated the Cappelli semolina as the ideal raw material for obtaining good finished products. Although that wheat variety leads to obtaining bread with a moderate GE value (85), it has received a good acceptability judgment (6.70) in contrast to the above-mentioned variety.

\section{Acknowledgements}

This work was financially supported by the Project "Misura 124-Cooperazione per lo sviluppo di nuovi prodotti, processi e tecnologie nei settori agricolo e alimentare, e in quello forestale" Avviso Pubblico relativo alla seconda fase di selezione di Progetti Integrati di Filiera-BURP n. 102 del 10/06/2010 with title "Approccio di filiera per elevare il contenuto nutrizionale di sfarinati da destinare alla trasformazione”.

\section{References}

[1] Reynolds, E.H. (1968) Mental Effects of Anticonvulsants and Folic Acid Metabolism. Brain, 91, 197-214. http://dx.doi.org/10.1093/brain/91.2.197

[2] Joshi, R., Adhikari, S., Patro, B.S., Chattopadhyay, S. and Mukherjee, T. (2001) Free Radical Scavenging Behavior of 
Folic Acid. Free Radical Biology \& Medicine, 12, 1390-1399. http://dx.doi.org/10.1016/S0891-5849(01)00543-3

[3] Kihlberg, I., Johansson, L., Kohler, A. and Risvik, E. (2004) Sensory Qualities of Whole Wheat Pan Bread-Influence of Farming System, Milling and Baking Technique. Journal of Cereal Science, 39, 67-84. http://dx.doi.org/10.1016/S0733-5210(03)00067-5

[4] Cornell, H.J. and Hoveling, A.W. (1998) Wheat: Chemistry and Utilization. Technomic Publishing Company, Lancaster, 43-53.

[5] Jones, C.R. and Ziegler, E. (1964) Principles of Milling. In: Hlynka, I., Ed., Wheat Chemistry and Technology, American Association of Cereal Chemists, St Paul, 111-193.

[6] Ziegler, E. and Greer, E.N. (1971) Principles of Milling. In: Pomeranz, Y., Ed., Wheat: Chemistry and Technology, American Association of Cereal Chemists, St Paul, 115-200.

[7] Mastromatteo, M., Danza, A., Lecce, L., Spinelli, S., Lampignano, V., Laverse, J., Contò, F. and Del Nobile, M.A. (2014) Effect of Durum Wheat Varieties on Bread Quality. International Journal of Food Science \& Technology, 49, 72-81.

[8] Mastromatteo, M., Danza, A., Guida, M. and Nobile Del, M.A. (2012) Formulation Optimization of Vegetable Flour Loaded Functional Bread. Part II: Effect of the Flour Hydration on the Bread Quality. International Journal of Food Science \& Technology, 47, 2109-2116. http://dx.doi.org/10.1111/j.1365-2621.2012.03077.x

[9] Lampignano, V., Laverse, J., Mastromatteo, M. and Del Nobile, M.A. (2013) Microstructure, Textural and Sensorial Properties of Durum Wheat Bread as Affected by Yeast Content. Food Research International, 50, 369-376. http://dx.doi.org/10.1016/j.foodres.2012.10.030

[10] Hahn, M., Vogel, M., Pompesius-Kempa, M. and Delling, G. (1992) Trabecular Bone Pattern Factor-A New Parameter for Simple Quantification of Bone Microarchitecture. Bone, 13, 327-330. http://dx.doi.org/10.1016/8756-3282(92)90078-B

[11] Chillo, S., Ranawana, D.V. and Henry, C.J.K. (2011) Effect of Two Barley $\beta$-Glucan Concentrates on in Vitro Glycaemic Impact and Cooking Quality of Spaghetti. LWT_Food Science and Technology, 44, 940-948.

[12] Monro, J.A., Mishra, S. and Venn, B.J. (2010) Baselines Representing Blood Glucose Clearance Improve in Vitro Prediction of the Glycaemic Impact of Customarily Consumed Food Quantities. British Journal of Nutrition, 103, 295305. http://dx.doi.org/10.1017/S0007114509991632

[13] Mastromatteo, M., Danza, A., Guida, M. and Del Nobile, M.A. (2012) Formulation Optimization of Vegetable FlourLoaded Functional Bread Part I: Screening of Vegetable Flours and Structuring Agents. International Journal of Food Science \& Technology, 47, 1313-1320. http://dx.doi.org/10.1111/j.1365-2621.2012.02975.x

[14] Sabanis, D., Lebesi, D. and Tzia, C. (2009) Effect of Dietary Fibre Enrichment on Selected Properties of Gluten-Free Bread. LWT-Food Science and Technology, 42, 1380-1389.

[15] Austin, A. and Ram, A. (1971) Studies on Chapati Making Quality of Wheat. Indian Council of Agricultural Research, New Delhi. Technical Bulletin, 31, 96-101.

[16] Belderok, B., Mesdag, J. and Donner, D.A. (2000) Bread-Making Quality of Wheat: A Century of Breeding in Europe. Editor on Behalf of ECAF, D. A. Donner, Kluwer Academic Pubblishers. http://dx.doi.org/10.1007/978-94-017-0950-7

[17] Dalgetty, D. and Baik, B. (2006) Fortification of Bread with Hulls and Cotyledon Fibers Isolated from Peas, Lentils and Chickpeas. Cereal Chemistry, 83, 269-274. http://dx.doi.org/10.1094/CC-83-0269

[18] Gomez, M., Ronda, F., Blanco, C.A., Caballero, P.A. and Apesteguia, A. (2003) Effects of Dietary Fibre on Dough Rheology and Bread Qualiy. European Food Research Technology, 216, 51-56.

[19] Park, H., Seib, P.A. and Chung, O.K. (1997) Fortifying Bread with a Mixture of Wheat Fibre and Psyllium Husk Fibre Plus Three Antioxidants. Cereal Chemistry, 74, 207-211. http://dx.doi.org/10.1094/CCHEM.1997.74.3.207

[20] Sangnark, A. and Noomhorn, A. (2004) Effect of Dietary Fiber from Sugarcane Bagasse and Sucrose Ester on Dough and Bread Properties. LWT-Food Science and Technology, 37, 697-704.

[21] Wang, J., Rosell, C.M. and Benedito De Barber, C. (2002) Effect of the Addition of Different Fibres on Wheat Dough Performance and Bread Quality. Food Chemistry, 79, 221-226. http://dx.doi.org/10.1016/S0308-8146(02)00135-8

[22] Sullivan, P., O’flaherty, J., Brunton, N., Arendt, E. and Gallagher, E. (2010) Fundamental Rheological and Textural Properties of Doughs and Breads Produced from Milled Pearled Barley Flour. European Food Research and Technology, 231, 441-453. http://dx.doi.org/10.1007/s00217-010-1297-4

[23] Angioloni, A. and Collar, C. (2009) Significance of Structuring/Prebiotic Blends on Bread Dough Thermo-Mechanical Profile. European Food Research and Technology, 229, 603-610. http://dx.doi.org/10.1007/s00217-009-1090-4

[24] Shewry, P.R., Popineau, Y., Lafiandra, D. and Belton, P. (2001) Wheat Glutenin Subunits and Dough Elasticity: Findings the Eurowheat Projiect. Trends in Food Science \& Technology, 11, 433-441. 
http://dx.doi.org/10.1016/S0924-2244(01)00035-8

[25] Sapirstein, H.D., David, P., Preston, K.R. and Dexter, J.E. (2007) Durum Wheat Breadmaking Quality: Effects of Gluten Strength, Protein Composition, Semolina Particle Size and Fermentation Time. Journal of Cereal Science, 45, 150161. http://dx.doi.org/10.1016/j.jcs.2006.08.006

[26] Lim, K.S. and Barigou, M. (2004) X-Ray Micro-Tomography of Cellular Food Products. Food Research International, 37, 1001-1012. http://dx.doi.org/10.1016/j.foodres.2004.06.010

\section{Abbreviations and Acronyms}

ACH: available carbohydrate content;

$F_{50 \%}$ : strength at $50 \%$ strain;

$F_{\text {break }}$ : strength at break;

FI: fragmentation index;

$F_{\text {max }}$ : maximum strength;

GE: glucose equivalent;

IDF: insoluble dietary fiber;

OSVR: object surface/volume ratio;

POV: percent object volume;

SDF: soluble dietary fiber;

St.Sp: structure separation;

St.Th: structure thickness;

Strain $_{\text {break: deformation at break; }}$

TDF: total dietary fiber. 